\title{
JUUL and other stealth vaporisers: hiding the habit from parents and teachers
}

\author{
Divya Ramamurthi, Cindy Chau, Robert K Jackler
}

Stanford Research into the Impact of Tobacco Advertising, Stanford University, Stanford, California, USA

\section{Correspondence to} Professor Robert K Jackler, Department of Otolaryngology, Stanford University, 801 Welch Road, Stanford, CA 94305, USA; jackler@stanford.edu

Received 18 April 2018 Revised 21 August 2018 Accepted 29 August 2018 Published Online First 15 September 2018

\section{Check for updates}

(C) Author(s) (or their employer(s)) 2019. No commercial re-use. See rights and permissions. Published by BMJ.

To cite: Ramamurthi $D$,

Chau C, Jackler RK.

Tob Control

2019:28:610-616.

\section{ABSTRACT}

Background Some consumers wish to use vapour devices discreetly so that family members, teachers and coworkers do not recognise their use of nicotine ortetrahydrocannabinol (THC) laden vapour.

Methods Stealthy vapour devices, as well as lowodour and low-vapour e-juices, were identified via a comprehensive online search between March and June 2018.

Results As evidence of their popularity, a search for 'stealth vaping' on YouTube found 18200 videos. A variety of cleverly designed vapour devices disguised as USB sticks, pens, remote controls, car fobs, smart phones, sweatshirt drawstrings and even asthma inhalers are on the market. JUUL, which resembles a USB stick, is the archetype of these devices and is especially popular among youth. A search of 'JUUL' on YouTube yielded 148000 videos with 57 videos having $>100000$ views. Searches on 'JUUL at school' (15 500), 'JUUL in class' (6840), 'hiding JUUL in school' (2030) and 'JUUL in school bathroom' (1040) illustrate the product's popularity among students. Some e-juices promote themselves as having low visibility plumes while others profess to be of subtle odour to avoid detection. Numerous techniques have been described to hide the exhaled vapour plume such as by swallowing it or blowing it into one's clothing or into a backpack.

Conclusions The vaping industry has demonstrated much ingenuity in devising discreet vaporisers and de-emphasising exhaled vapour plumes and their aroma. The US market for vaping devices with stealthy characteristics is anything but inconspicuous, with JUUL alone accounting for $70.5 \%$ of sales (July 2018).

\section{INTRODUCTION}

Teens have long sought to hide their tobacco and marijuana use from disapproving parents and teachers. In the past, this meant secreting cigarettes and joints in out-of-the-way places and smoking surreptitiously out of sight. Recently, a new means of covert nicotine and marijuana use is rapidly gaining popularity. A proliferation of stealth vaporisers, devices which resemble ordinary items which may not draw attention from adults, are increasingly popular. A search for 'stealth vaping' on YouTube found 18200 videos (June 2018). This family of devices may be left on a teen's bedside table and not be recognised for what it is by a parent. This is typified by the meteoric rise of JUUL, an e-cigarette which closely resembles a USB stick. ${ }^{1-5}$ JUUL is increasingly popular among high school students who often use it during school in bathrooms, staircases or even in classes. ${ }^{6}$
The purpose of this study is to describe the diversity of stealth vaporisers, devices disguised to resemble something other than what they are, to enable inconspicuous vaping. This includes vaporisers of nicotine and tetrahydrocannabinol (the psychoactive constituent of marijuana) contained in e-liquid, oil, concentrates and dry marijuana flower. In addition, we explore vaping liquids marketed as generating a less conspicuous exhaled vapour and methods used by consumers to conceal the exhaled vapour plume.

\section{METHODS}

Identification of stealth devices and e-juices was conducted by online searches (Google) between March and June 2018. Brand websites and social media postings, consumer reviews of vaping products, media articles and YouTube videos were the major sources. Search terms to identify brands include the following: a combination of vapour brands (eg, JUUL), vaping terms (eg, e-cigarette, e-juice, e-liquid), synonyms implying covert use (eg, stealth, discreet, subtle, inconspicuous) and forms of ordinary objects we knew to be adopted into vaporisers (eg, pens, asthma inhalers). We also sought other sleek vaporiser devices that emulate JUUL in their design and searched YouTube for videos illustrating ways consumers use secret devices and hide their vapour plumes (eg, hiding JUUL in school or from parents).

\section{RESULTS}

\section{Products resembling USB sticks}

As of July 2018, JUUL represents an impressive $70.5 \%$ of the entire US convenience store market for vapour products making it of unique importance among stealth vaping devices. ${ }^{1}$ Other leading brands (Vuse at 10.8\%, Blu at 5.6\%, MarkTen at $7.7 \%$ ) either recently introduced, or plan to introduce, small stealthy pod-based devices (Alto, MyBlu, Elite). As one gauge of its popularity, a search on 'JUUL' on YouTube (June 2018) yielded 148000 videos with 57 videos having $>100000$ views. The company maintains that: 'JUUL is for adult smokers seeking a satisfying alternative to cigarettes. ${ }^{7}$ Nevertheless, the device is increasingly popular among teens. ${ }^{34}$

Each JUULpod contains $0.7 \mathrm{~mL}$ of liquid with $5 \%$ of nicotine by weight or $59 \mathrm{mg} / \mathrm{mL}$ in a mixture of propylene glycol, glycerol and benzoic acid as the vehicle. This is among the highest concentration offered by e-juice vendors and approximately an equivalent dose to that contained within an entire pack of cigarettes. ${ }^{7}$ A few companies advertise JUUL-compatible pods including EonSmoke, 




Juul

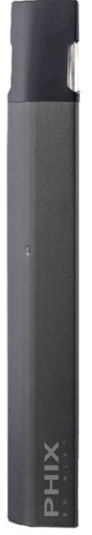

Phix

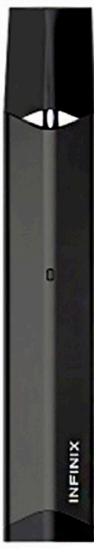

Infinix

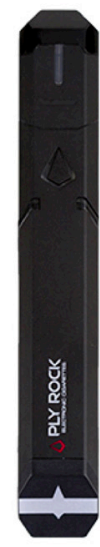

Ply Rock

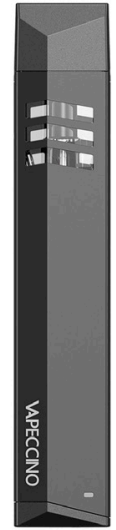

Vapeccino

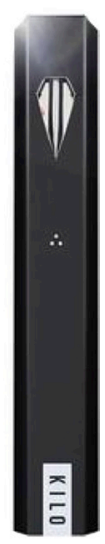

Kilo
Figure 1 Vapour devices which resemble USB memory sticks. Emulating the success of JUUL, the market has seen a proliferation of similar stealth vaporisers.

Airbender, Ziip Pods and Fuma. ${ }^{8}$ These alternative pods are usually cheaper, have nicotine content slightly lower or higher than JUULpods and are available in a wider range of flavours. Reviews of these alternative products are mixed with complaints of leakage and harsher flavouring. ${ }^{10}$ Google trends shopping data shows that searches for these alternative products are far fewer than searches for JUULpods. ${ }^{11}$ In addition, consumers sometimes try to refill their JUULpods with less expensive e-juice. The popularity of this is witnessed by a YouTube search on 'refilling JUULpods' which yielded 4830 videos. The JUUL website clearly cautions consumers against re-filling JUULpods with other liquids through the following warning statement: 'For health and safety concerns, please do not attempt to refill or open your JUULpods. To maintain product quality JUULpods are not designed for refills nor re-use."7

The extraordinary success of JUUL has led to a proliferation of other sleek vaporiser devices that emulate JUUL in their design (figure 1). Advertising of Smok Infinix, a nicotine vaporiser shows the product hidden in a woman's handbag alongside common everyday items such as lipstick, alongside the description: 'It has (sic), sleek appearance, the mini body can be your best partner wherever you go. ${ }^{12}$ An instructional video for Limitless Pulse Pod's e-cigarette has instructions on activating its 'stealth mode' so that there is no colour illumination when you inhale. ${ }^{13}$ The Suorin iShare e-cigarette vaporiser is promoted on a tobacco retail website as an: 'ultra portable system that is perfect for users looking for a sleek and all-day vaping device.' ${ }^{14}$ Other e-cigarette brands with stealth devices include Vapeccino's Mate 1, Kilo $1 \mathrm{k}$ ultra portable system, XFIRE, PHIX and The Secret Sauce Stix Ultra Portable Pod System. The Sutra Vape Dash and Kandy Pen are e-liquid and THC oil vaporisers that include refillable cartridges. While devices resembling JUUL have vastly smaller sales, YouTube searches on 'PHIX vape' (5270), 'Infinix vape’ (2520), 'Ply Rock vape’ (1470), 'Vapeccino vape’ (1210) indicate a degree of popularity.

The Pax Era, which is described as 'low profile' and 'ultimate discretion', is a prefilled cannabis oil vaporiser. ${ }^{15}$

\section{Resembling asthma inhalers}

Discreet Vape's PUFFiT dry herb (ie, marijuana flower) and THC concentrate vaporiser markets a product modelled on an asthma inhaler (figure 2). ${ }^{16}$ According to the description: 'The design

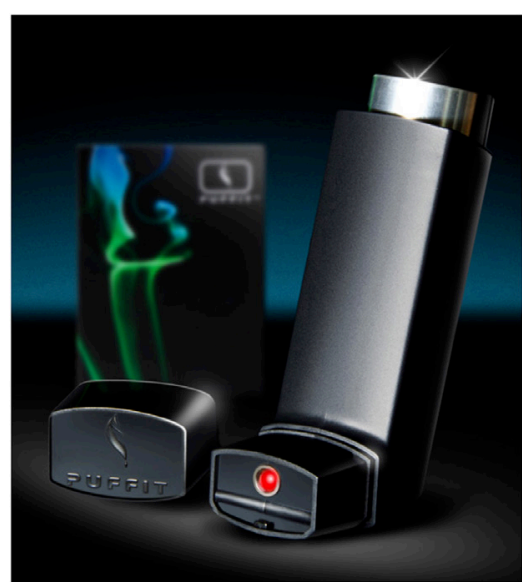

PUFFiT

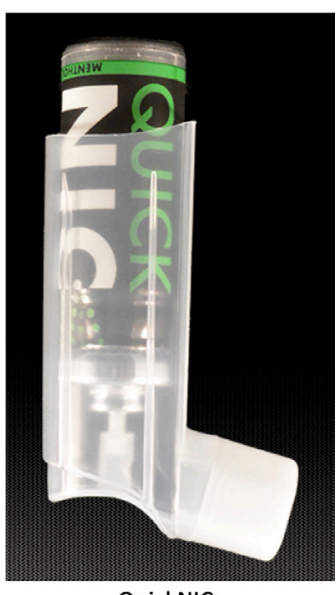

QuickNIC
Figure 2 Discreet vaporisers which resemble asthma inhalers. Pufflt's description says: 'The design was created this way on purpose so that your vaping sessions can be done in a more stealthy fashion. While other vaporizers might give you away, using the Pufflt 2 Vaporizer will ensure that your experience is both private and discreet'.

was created this way on purpose so that your vaping sessions can be done in a more stealthy fashion. While other vaporizers might give you away, using the PuffIt 2 Vaporizer will ensure that your experience is both private and discreet. ${ }^{16}$ Another design addition that adds to the discreetness of the product is 'haptic feedback', a function that notifies users by vibration rather than lights when heating is complete. ${ }^{16}$ QuickNIC is another brand that is designed to simulate an asthma inhaler (figure 2). ${ }^{17}$ The 'non-prescription nicotine inhaler' contains a nicotine dose that is equivalent to about two entire packs of combustible cigarettes. Each breath from the QuickNIC device delivers $25 \mathrm{mg}$ of nicotine to the lungs. The manufacturer recommends its use: 'in situations where smoking and vaping are restricted, QuickNIC allows you to discreetly breathe nicotine.' The product description goes on to say that the device is: 'small, discreet and portable ... Each breath of QuickNIC is absorbed and not exhaled, so no one will even know you're using it'. Advertising for the product is accompanied by the slogan: 'nicotine anytime anywhere'. Inhalers are also on the market as a form of nicotine replacement therapy. Although in comparative studies oral inhalers were preferred to gums and lozenges, they are still not very popular. ${ }^{18}$

\section{Resembling pens}

There are a number of brands that manufacture stealth marijuana and nicotine vaporisers that resemble pens. (figure 3) The Vape

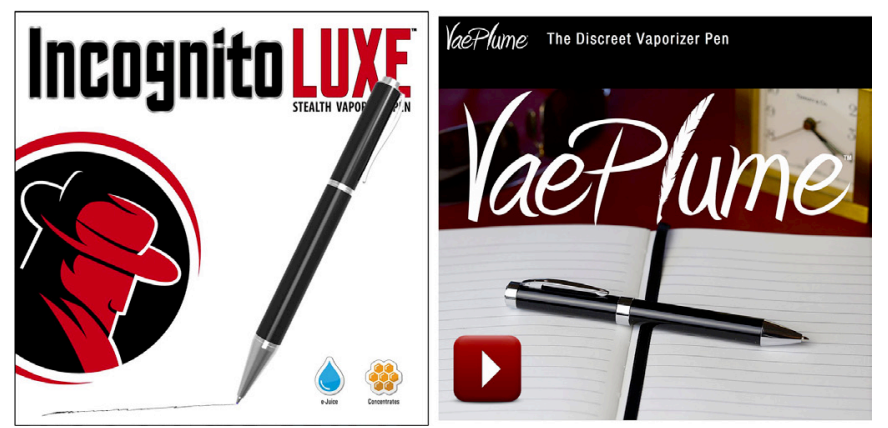

Figure 3 Vaporisers disguised as pens include Incognito Luxe, marketed as a 'Stealth vaporizer pen' and VaePlume marketed as a 'Discreet vaporizer pen'. 

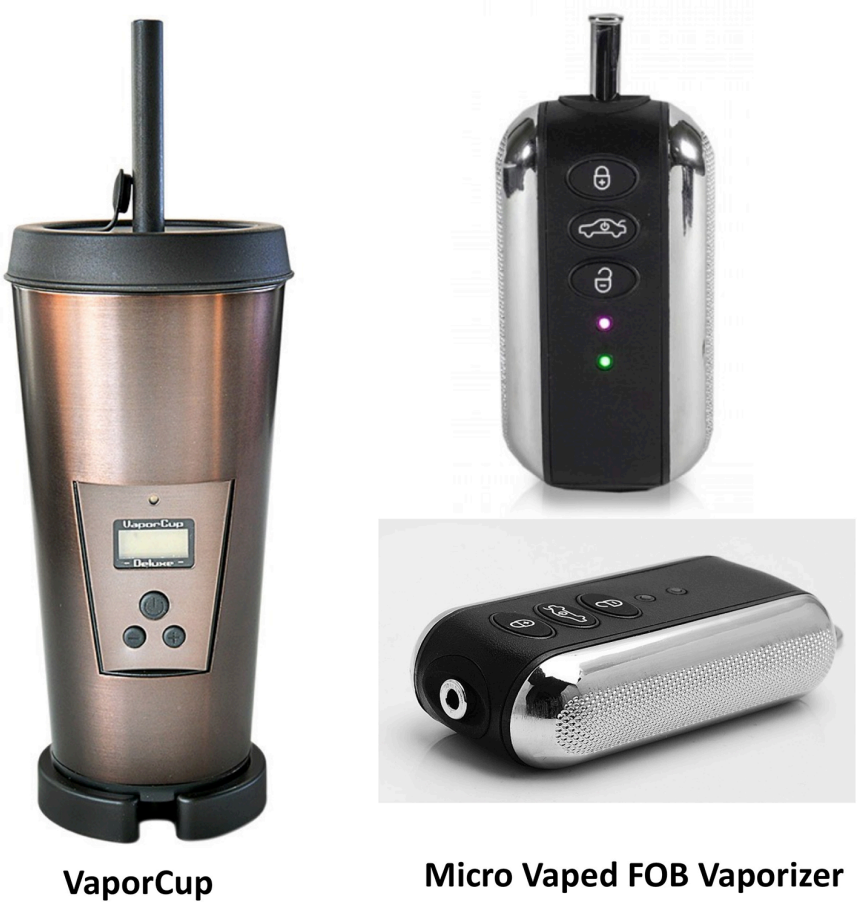

Micro Vaped FOB Vaporizer

Figure 4 VaporCup is described as a: 'travel mug style design blends in with life to assure your privacy'. Micro Vaped FOB is described as a 'car key vaporiser' for 'low key vaping'. The trunk open button is the on/ off switch and the lock and unlock buttons vary the temperature.

markets a 'Incognito Luxe Stealth Vaporizer Pen', promoted as: 'the type of covert device you would find in a Spy movie'. ${ }^{19}$ The brand prides itself in being a fully functional pen of luxurious quality. 'Most people never figure out the true nature of this duplicitous device, even after writing with it for days.' The pen is compatible with e-juices, as well as with marijuana concentrates and oils. Micro Vaped V4 Vaporizer Pen is a marijuana concentrate vaporiser described as a: 'fine writing pen for discreet vaporization'. ${ }^{20}$ VaePlume's Discreet Vaporizer Pen is marketed as 'discretion in form and function'. ${ }^{21}$ According to the product description it is for: 'social, sophisticated, and professional individuals who are actively breaking 'the stoner' stereotype'. The product: 'allows you to practice discretion in living your lifestyle'. The Grasshopper's pen vaporiser is described as: 'born out of a need for a great portable vaporizer'. The device also has a top button that turns the device on and off. ${ }^{22}$

\section{Resembling car fob}

Micro Vaped manufactures a marijuana vaporiser that resembles a key fob commonly used in automobile for on-the-go stealth vaping (figure 4). ${ }^{23}$ The lock and unlock buttons, instead of opening a car door, are used to switch from the six predesigned heat settings. The button with the trunk opening icon is the on/ off switch. The brand markets the vaporiser as the ultimate in 'low-key' vaping.

\section{Resembling a coffee cup}

VaporCup manufactures a marijuana vaporiser in the form of a coffee travel mug describing it as: 'designed for discreet use' (figure 4). ${ }^{24}$ The mug comes with a removable 'privacy sleeve' to mask its digital display. VaporCup is marketed as a: 'travel mug style design blends in with life to assure your privacy'.

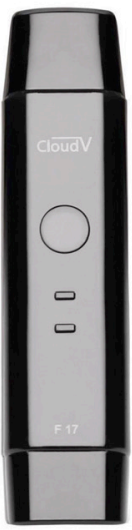

Cloud V F17

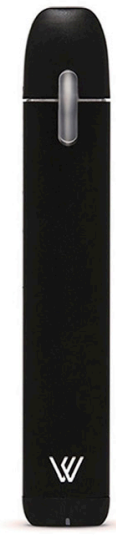

My Von Erl

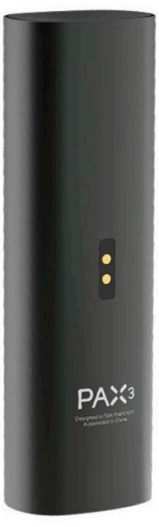

$\operatorname{Pax} 3$

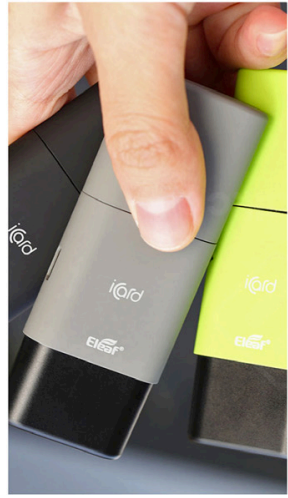

eleaf iCard
Figure 5 Vaporisers which resemble small electronic devices such as a remote control, MP3 player or iPod.

\section{Resembling small electronic devices}

Several vaporisers resemble small electronic products such as the MP3 player, voice recorder or remote controls (figure 5). Cloud V's F17 marijuana vaporiser is described as a: 'discreet, portable and functional... and it fits in the palm of your hand" 25 with its cap on Eleaf's iCard nicotine delivery device resembles an iPod. ${ }^{26}$ The device is available in bright colours that brings to mind highlighters. Other examples of devices that resemble electronic devices include the e-cigarette brand My Von Erl and PAX 2 and PAX 3 which are dry herb vaporisers (ie, vaporisers of dried tobacco leaf or marijuana).

\section{Resembling a mobile phone}

The Suorin Air Pocket Vape, a slim e-cigarette vaporiser, produced by Foxconn, is advertised, as: 'so small that it can fit in your pocket and even your wallet... Smaller than the average smartphone...27 E-cigarette manufacturer Veppo, which also brands and sells the Suorin vaporiser, says the Suorin Pod Vape gives: 'new meaning to the idea of covert vaping'. ${ }^{28}$ Veppo markets the Suorin product as: 'Mini size. Huge freedom' and the 'modern stealth vaporizer' (figure 6). The DaVinci Ascent marijuana vaporiser resembles a flip phone and is described as: 'sleek, stylish, and discreet'. ${ }^{29}$

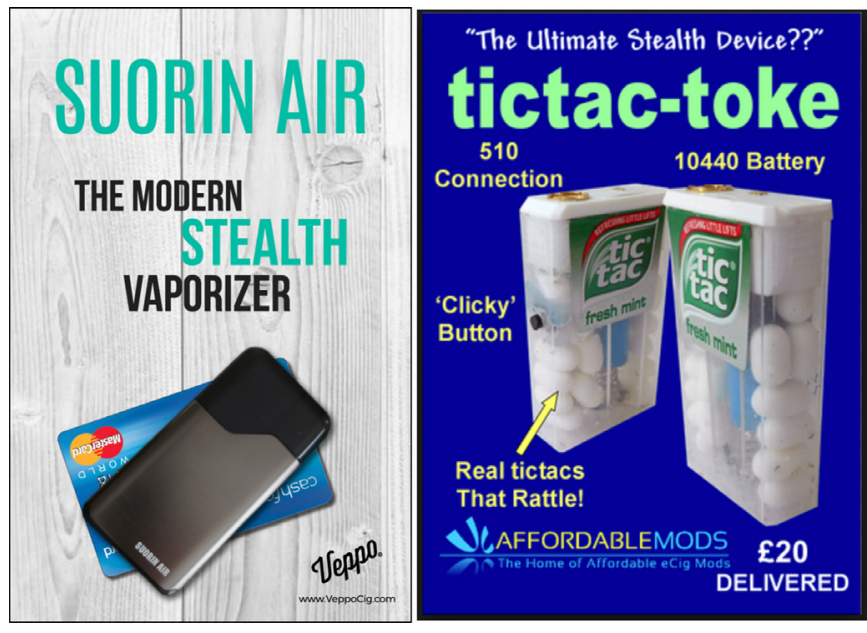

Figure 6 Sourin Air is a credit card-sized device marketed a 'modern stealth vaporizer'. Hidden within a candy dispenser, tictac-toke is marketed as 'The ultimate stealth device'. 

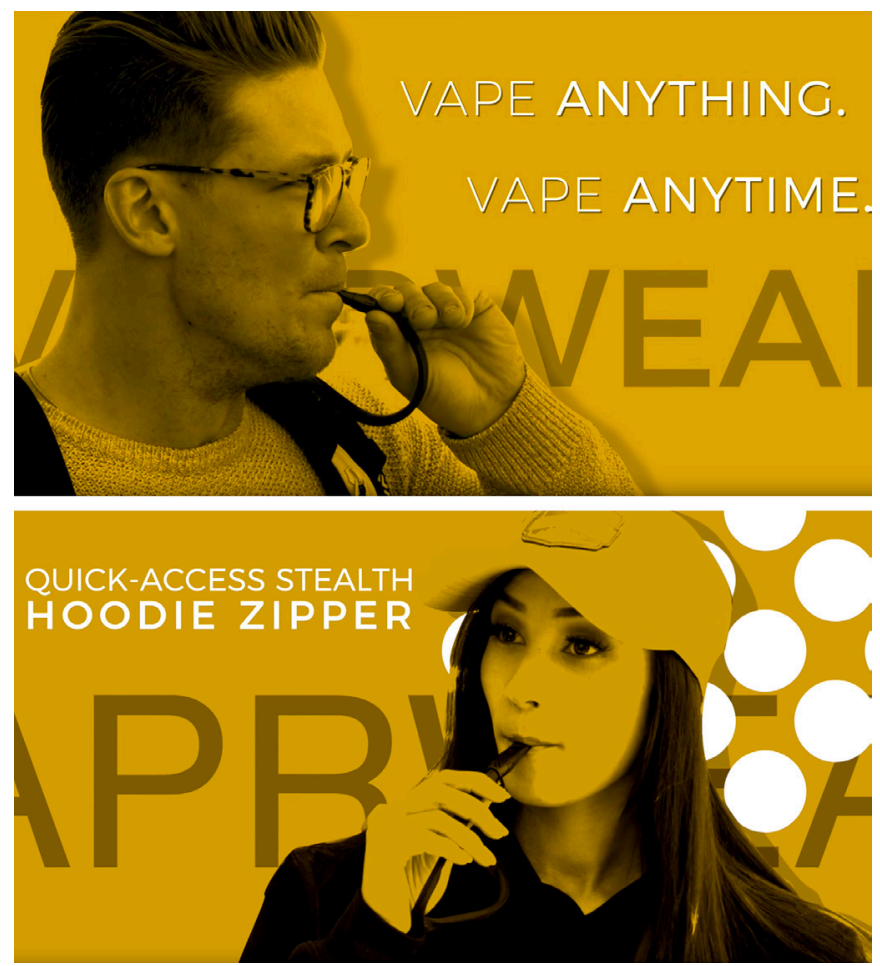

Figure 7 The Vaprwear HydroVape backpack (above) has the vapour delivery system built into the shoulder strap. The Vaprwear 'stealth hoodie zipper' (below) secretes all components of the vaporiser within its drawstring.

\section{Resembling candy container}

Affordable Mods offers the tictac-toke marijuana vaporiser in which the vaping apparatus is secreted within a Tic Tac candy container. $^{30}$ The container is divided into two parts, with one containing the vape generator and battery and the other filled with actual Tic Tac candies (figure 6).

\section{Wearable devices}

Vaprwear manufactures a line of hoodies and backpacks that promote: 'discreet, hands-free vaping integrated into wearable products'. ${ }^{31}$ Their discreet vaping designs are marketed with the slogans: 'easy vapor delivery anywhere, anytime', 'more than meets the eye' and 'it's gear with a higher purpose'. The later slogan connotes potential use for THC containing vapours. The 'stealth hoodie zipper', available in styles for both men and women, comes with a drawstring that contains the following: a concealed battery, e-juice cartridge, vaporiser and extendable mouth piece. The system is connected by a 'medical grade hose system' (figure 7). The brand also manufactures the 'HydroVape backpack'. According to the manufacturers, the backpack is designed for 'active lifestyles' and is constructed with enough room for: 'gear or a laptop and school supplies (bold added)'.

\section{Vaporisers with 'stealth' their brand name}

The Kado Stealth is a nicotine vaporiser that promotes itself as: 'the next small thing in vaping technologies'. ${ }^{32}$ According to the brand, its mission is to: 'create ergonomic and portable products while maintaining a contemporary and discreet design suited for any lifestyle or occasion'. The brand uses modern designs that: 'leave no trace behind'.

A number of vaporisers have product names suggesting they are discreet or stealthy, even though they have similar appearance
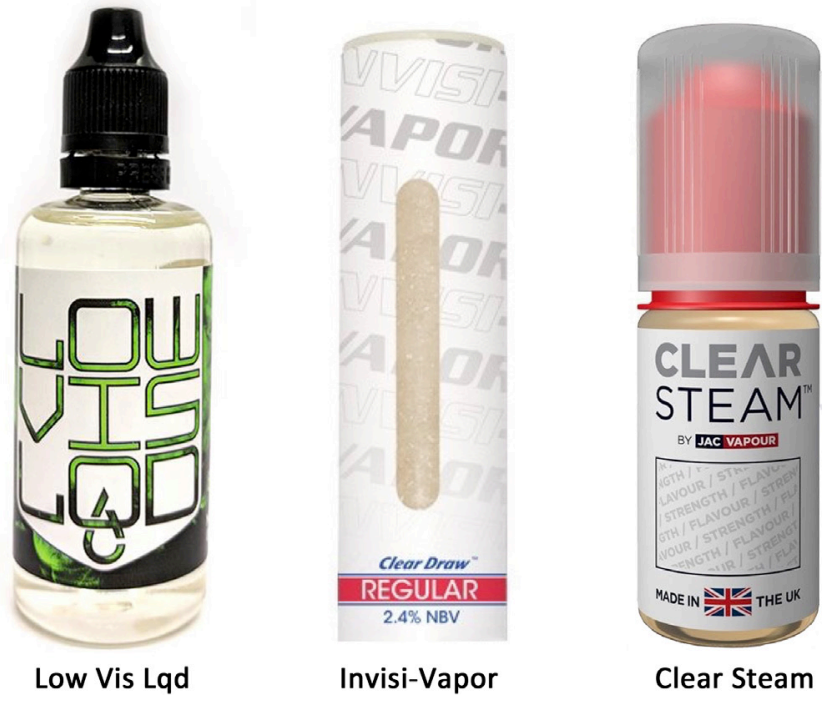

Figure 8 E-juice brands manufacture low visibility e-juices that deemphasise the vapour they produce to promote stealth vaping.

to other vaporisers on the market and possess no distinguishing covert features. The Zig-Zag Stealth Vaporizer, while it carries a name connoting an inconspicuous design, is shaped like a typical cigarette. ${ }^{33}$ The Kind Pen vaporiser named Discreet is a fairly typical rectangular box with a prominent mouth piece. ${ }^{34}$ Other brands in this category includes Vape Ape's Stealth Skillet, Kind Distribution's Stealth Bhomber and TeslaCig's Stealth Mod.

\section{Low vapour}

Inconspicuous vaporisers, or the e-juice they use, may be designed to de-emphasise the vapour they produce. For example, the vapour produced by JUUL is relatively subtle. ${ }^{7}$ Makers of e-liquids also market inconspicuous vapour products, with a greater concentration of propylene glycol and less glycerin. ${ }^{35}$ Adding water to dilute the vapour is another method. To diminish this tell-tale sign of vaping, Jac Vapour markets Clear Steam Vapourless brand of e-liquid that they claim leaves behind little visible cloud (figure 8). ${ }^{36}$ White Cloud Electronic Cigarettes manufactures Invisivapor liquid cartridges which are described as 'especially innovative as it produces almost no noticeable vapour at all, which makes it ideal for public use'. ${ }^{37}$

\section{Techniques for secreting vapour plume}

The vapour plume may be hidden by any number of techniques. $^{35} 38$ The 'deep inhale' method takes advantage of the fact that vapour that is held into the lungs for longer periods becomes less prominent. The 'second inhale' technique involves a subsequent inhalation of air to dilute the vapour. Swallowing the vapour during exhalation is yet another method. A student recommended on YouTube exhaling into a backpack or under clothing. ${ }^{39}$ Exhaling into a napkin or paper towel has also been recommended.

\section{Low odour e-juices}

One aspect of stealthiness is low odour. Due to vaping flavoured e-juices, some school bathrooms have been said to smell like fruit stands. ${ }^{6}$ The odour JUUL produces has been described as: 'subtle and could easily be mistaken for a lotion or body spray'. 6 There are also flavourless e-juices available on the market which claim that they have 'no fragrance'. ${ }^{40}$ Manufacturers of Suorin Air note that the smell of the: 'vape dissipates after a few minutes'. ${ }^{27}$ 


\begin{tabular}{lc}
\hline $\begin{array}{l}\text { Table } 1 \text { Number of YouTube videos related to stealth vaping (as of } \\
\text { June 2018) }\end{array}$ \\
\hline YouTube search terms & No. of videos \\
\hline 'Stealth vaping' & 18200 \\
'Discreet vaping' & 2810 \\
'Vaping at work' & 80100 \\
'Vaping at church' & 5920 \\
'Vaping in a hospital' & 7000 \\
'Vaping at airport' & 4940 \\
'JUUL at work' & 7980 \\
'JUUL at church' & 1230 \\
'JUUL in a hospital' & 995 \\
'JUUL at airport' & 1180 \\
\hline
\end{tabular}

Vaporisers have also been touted as enabling use of THC oils without the distinctive hemp odour of marijuana. ${ }^{41}$ The brand Wake Vape's Stealth e-liquid is described as a mixing agent that can hide the smell of marijuana concentrates with the e-juices citrus described as: 'Scientifically formulated to mask the potent smell of herbs, ${ }^{42}$

\section{Locations for discreet vaping}

There are multiple reasons for a consumer to engage in inconspicuous vaping. An obvious one is that it is a way of getting a nicotine or THC dose in a place in where smoking and vaping are not permitted. YouTube searches on 'vaping at work' (80 100), 'vaping at the airport' (4940), 'vaping in a hospital' (7000) and 'vaping in church' (5920) illustrate the popularity of stealth vaping. JUUL is also heavily represented in these categories (table 1$)$.

\section{Stealth vaping among youth}

Much attention has been focused on the popularity of stealth vaping, especially JUUL, among youth. The widespread use of JUUL among students is illustrated by the number of YouTube videos related to JUUL use at school (table 2). By way of illustration, a large number of YouTube videos are of this genre: for example, 'JUUL at school' (15 500), 'JUUL in class' (6840) and 'JUUL in the school bathroom' (1040). Of most direct relevance to stealth vaping were the YouTube videos describing 'hiding JUUL': 'in school' (2030), 'from teacher' (531), 'from parents' (1990) and 'at home' (1230).

\begin{tabular}{lc}
\hline $\begin{array}{l}\text { Table } 2 \\
\text { of June 2018) }\end{array}$ & No. of videos \\
\hline YouTube search terms & 15500 \\
\hline 'JUUL at school' & 1040 \\
'JUUL in school bathroom' & 6840 \\
'JUUL in class' & 2480 \\
'JUUL at camp' & 2030 \\
'Hiding JUUL in school' & 1230 \\
'Hiding JUUL at home' & 531 \\
'Hiding JUUL from teacher' & 1990 \\
'Hiding JUUL from parents' & 758 \\
'JUUL school suspension' & 451 \\
'JUUL in a Sharpie' & 6510 \\
'JUUL flavors' & $148000^{*}$ \\
\hline 'JUUL' &
\end{tabular}

*57 videos have $>100000$ views.

\section{DISCUSSION}

An individual seeking to vape covertly needs to consider several factors that reveal the activity. The first is the device itself, most of which either come in sizes and shapes reminiscent of cigarettes, large cigars or boxes with nipples making their purpose rather obvious. The second is the vapour plume which is often more prominent than with a traditional cigarette. The third is the residual smell which may be distinctive, particularly for sweet and fruity flavours.

The devices described in this paper illustrate the creativity of vapour device manufacturers in designing vaporisers cloaked to disguise their actual purpose. While most of these devices employ e-liquids containing nicotine, some are capable of delivering THC via liquid, oil or even dried flowers. One common feature of stealth vaporisers is that they either lack a mouthpiece, which would be an obvious giveaway, or have a retractable nipple. Most are cleverly designed to emulate ordinary objects such as USB memory sticks, pens, MP3 players, cell phones, coffee mugs, car fobs or even candy dispensers. Most are small enough to be secreted into a pocket or purse. Numerous YouTube videos, with their impressive number of 'likes' testify to the popularity of discreet vapour devices, especially among youth who often use them in schools. While the primary focus of this paper is commercially available stealth vaporisers, consumers sometimes make postmarket modifications to enhance the stealthiness of their devices. Individuals hollow out commonplace items such as Sharpie markers, TV remote controls, game controllers and so on (figure 9).

Clandestine smoking in school has a long history as illustrated by the popular 45 -year-old song by the group Brownsville Station: 'Smokin' in the boys room' (1973). Given the ready availability of inconspicuous devices and plume-reducing methods, inhibiting school vaping is a challenge. To curb stealth vaping, principally aimed at curtailing the JUUL craze, some schools have banned flash drives. ${ }^{43}$ Concerned about the frequency of vaping in school bathrooms, districts are seeking to counter the trend. ${ }^{44}$ Yorktown High school went so far as to remove the main doors from student bathrooms to dissuade vaping. ${ }^{6}$ A number of high schools in New York recently began testing vapour detectors using sensors marketed by a school safety company, Digital Fly. ${ }^{45}$ Noting the rapid rise of tobacco-related disciplinary actions, a metropolitan Chicago school district plans on installing vapour detectors in washrooms. ${ }^{47}$

Use of traditional cigarettes among US high school student dropped from 15.8\% to $7.6 \%$ between 2011 and 2017 while e-cigarettes increased from $1.5 \%$ to $11.7 \% .^{48}$ In 2014, American high school students used vapour products more than combustible cigarettes for the first time. ${ }^{49}$ Given the exceptional rise of JUUL use by teens since its introduction in July 2015, the per cent of high school students using e-cigarettes is likely higher in 2018 .

JUULpods use nicotine salts which according to the manufacturer allows the nicotine content to be quickly absorbed. ${ }^{50}$ Among 30-day users of JUUL ages 15-24, only 37\% were aware that JUUL always contained nicotine. ${ }^{51}$ JUUL's high nicotine concentration raises concern that it is serving as a gateway to nicotine addiction among a sizeable number of adolescents. Studies show that nicotine-addicted teen vapers often adopt use of more dangerous combustible tobacco types. ${ }^{52-56}$ The rising use of vapour devices in schools may portend use of other substances. A study found that adolescent smokers who reported smoking on high school property were nearly three times more likely to engage in binge drinking and nearly four times more 


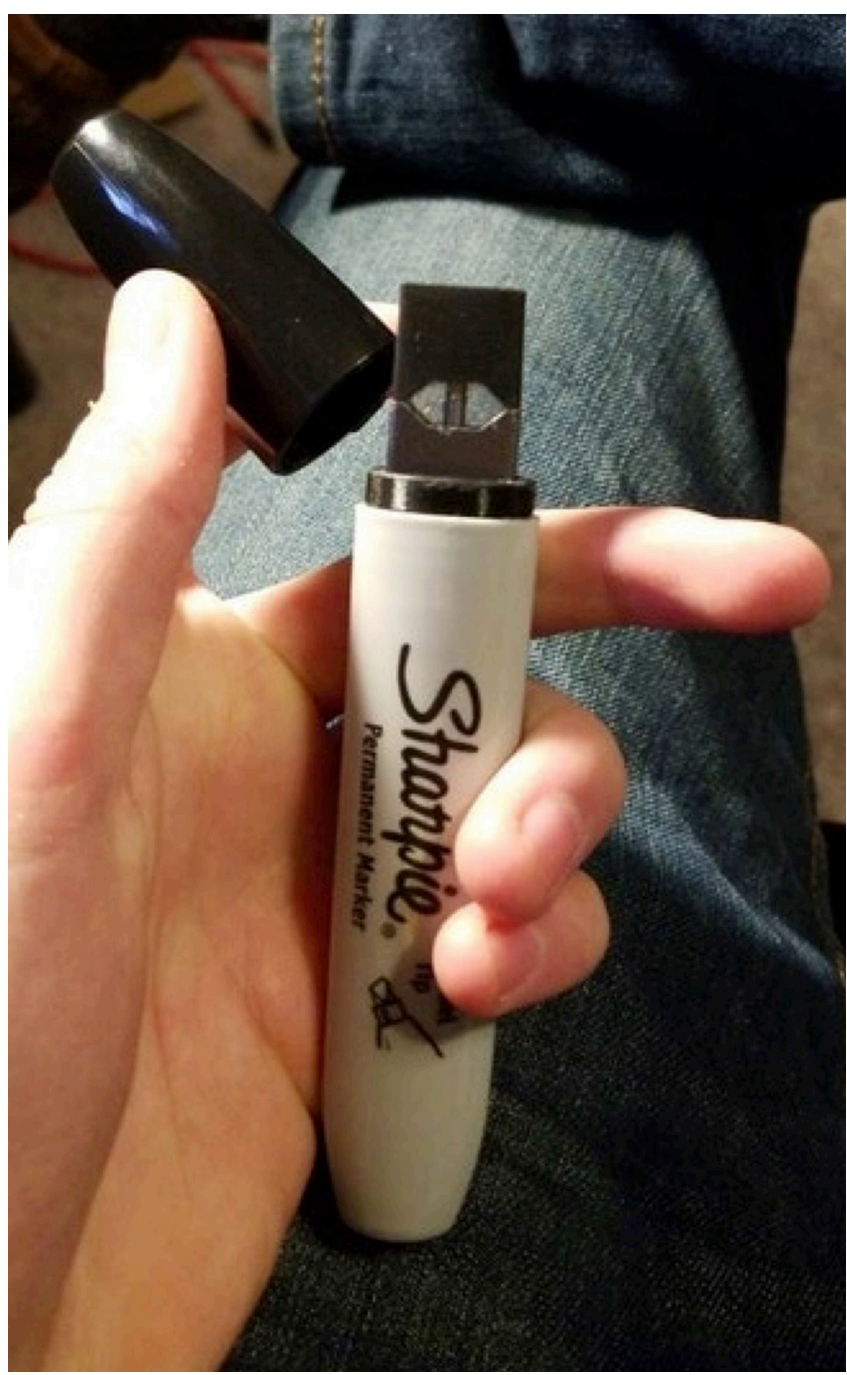

Figure 9 Teens are creative in inventing ways to hide their vaporiser devices to avoid discovery by parents and teachers. ${ }^{65} \mathrm{~A}$ number of YouTube videos illustrate how to hide a JUUL in a Sharpie marker, one of which has $>35000$ views.

likely to smoke marijuana or use cocaine compared with student smokers who did not smoke on campus. ${ }^{57}$

Regulators seeking to reign in stealth vapour devices face challenges. $^{58-60}$ Technically, defining the concept of stealthiness is difficult. Even were current generation vaporisers restricted from the marketplace, such as those shaped like USB devices, companies could innovate in myriad ways to circumvent any such regulation. In addition, postmarket modification by consumers to disguise a vaping device cannot realistically be controlled.

This study has some limitations. Stealth devices and e-juices were captured at a particular window of time and, although it covers the representative types, it does not represent the entirety of the market. In addition, the stealth device market is undergoing rapid change, and some of the products offered by the brands during the period of data collection may not be available at the time of publication of this paper. The number of YouTube videos retrieved from searches are sometimes inflated by off-topic videos. A study of JUUL's marketing found that $80 \%$ of YouTube videos retrieved in the search results were related to JUUL e-cigarettes. ${ }^{2}$

To date, JUUL has been nearly exclusively an American phenomenon. In its first foray into a market outside of the USA, in February 2018 JUUL entered the Israeli market with its $59 \mathrm{mg} /$ $\mathrm{mL}$ nicotine product. In July 2018, JUUL was launched in the UK with $20 \mathrm{mg} / \mathrm{mL}$ nicotine pods to be compliant with the European Union Tobacco Product Directive standards. ${ }^{61}$ Israel is considering adopting the European standard. ${ }^{62}$

Alerted by the rapid rise in JUUL use among American students, in April 2018 the US Food and Drug Administration undertook 'enforcement actions' against retail establishments selling JUUL to youths. Letters were sent to JUUL Labs, requesting the company's documents with regard to product marketing, product design and research on health, toxicological or behavioural effects. This information might help to explain the youth appeal of their product. ${ }^{6364}$

\section{What this paper adds}

- Stealth vaping devices enable covert use of nicotine and THC.

- A variety of vapour devices have been disguised as ordinary items such as USB sticks, pens, remote controls, car fobs, smart phones, sweatshirt drawstrings and even asthma inhalers.

- The extraordinary popularity of JUUL among teens may be due in part to the fact that parents and teachers do not recognise it as a vaping device.

- Stealthiness includes e-juices which are marketed for their low visibility plume and/or subtle odour.

- YouTube videos describe numerous techniques for secreting the exhaled plume by exhaling under clothing or into backpacks, often in the school setting.

Contributors RKJ conceived the project. RKJ and DR wrote the manuscript. CC assisted in manuscript and image editing. All three authors are responsible for research on stealth vaporisers.

Funding The authors have not declared a specific grant for this research from any funding agency in the public, commercial or not-for-profit sectors.

Competing interests None declared.

Patient consent Not required.

Provenance and peer review Not commissioned; externally peer reviewed.

\section{REFERENCES}

1 Craver R, 2018. JUUL continues to expand market share gap with Vuse. https://www. journalnow.com/business/juul-continues-to-expand-market-share-gap-with-vuse/ article_381b4da5-a13e-58a8-9807-88d1bb6bd1c8.amp.html (accessed 15 Aug 2018).

2 Huang J, Duan Z, Kwok J, et al. Vaping versus JUULing: how the extraordinary growth and marketing of JUUL transformed the US retail e-cigarette market. Tob Control 2019;28:146-51.

3 LaVito A, 2018. JUUL built an e-cigarette empire. Its popularity with teens threatens its future. https://www.cnbc.com/2018/08/03/juul-e-cigarettes-popularity-amongteens-concerns-schools-fda.html (accessed 15 Aug 2018).

4 Chaker AM. Schools and parents fight a JUUL e-cigarette epidemic. The Wall Street Journal 2018 (accessed 12 Jun 2018).

5 Kavuluru R, Han S, Hahn EJ. On the popularity of the USB flash drive-shaped electronic cigarette Juul. Tob Control 2019;28:110-2.

6 Ibarra $A B$. These tiny inhalers could be a big health risk for students and teachers can't see them: Sacramento Bee, 2018. (accessed 12 Jun 2018)

7 . JUUL. https://www.juulvapor.com/ 2018. (accessed 12 Jun 2018).

8 Electric Tobacconist. JUUL compatible pods. https://www.electrictobacconist.com/juulcompatible-pods-c80 (accessed 12 Jun 2018).

9 Unique Wholesale Vapor. Fuma Pods. http://uniquewholesale.biz/fuma-pods-assortedflavors-4-pack/ (accessed 12 Jun 2018).

10 Redditt. Review of JUUL pod alternative. https://www.reddit.com/r/juul/comments/ 8gz8om/review_of_juul_pods_alternative_eonsmoke_pods/\#bottom-comments (accessed 12 Jun 2018)

11 Google trends. JUUL pod alternatives. https://trends.google.com/trends/explore?date= now\%201-H\&geo=US\&q=Juul\%20pods, Eon\%20Smoke\%20pods,Fuma\%20pods, Ziip\%20pods (accessed 12 Jun 2018).

12 Smok. Infinix https://www.smoktech.com/kit/infinix (accessed 12 Jun 2018). 
13 Limitless Mod Company. Pulse pod system instructions. https://limitlessmodco.com/ limitless-pulse-pod-system-instructions (accessed 12 Jun 2018).

14 Vapor DNA. Suorin iShare Ultra Portable System Starter Kit. https://www.vapordna. com/Suorin-iShare-Ultra-Portable-System-Starter-Kit-p/suisha.htm (accessed 4 Jun 2018).

15 Pax. Pax Era. https://www.paxvapor.com/era/ (accessed 12 Jun 2018).

16 Got Vape. Puffit 2 Vaporizer by discreet vape description. https://www.gotvape.com/ puffit-2-portable-vaporizer.html (accessed 12 Jun 2018).

17 QuickNIC. Nicotine anytime anywhere. https://quicknicmist.com/ (accessed 12 Jun 2018).

18 Schneider NG, Cortner C, Justice M, et al. Preferences among five nicotine treatments based on information versus sampling. Nicotine Tob Res 2008;10:179-86.

19 The Vape Co. Incognito luxe stealth vaporizer pen. https://thevapeco.com/product/ incognito-luxe-stealth-vaporizer-pen/ (accessed 12 Jun 2018).

20 VaporNation. Microvaped V4 Nano Vaporizer. https://www.vapornation.com/microvaped-nano-vaporizer.html (accessed $10 \mathrm{Apr}$ 2018).

21 VaePlume. https://www.vaeplume.com/. (accessed 12 Jun 2018).

22 Grasshopper. The Grasshopper: a revolution in portable Vaporizer Technology. https:// www.grasshoppervape.com/information/grasshopper (accessed 12 Jun 2018).

23 VaporNation. Microvaped FOB vaporizer. https://www.vapornation.com/micro-vapedfob-vaporizer.html (accessed 10 Apr 2018).

24 VaporCup. https://vaporcup.com/. accessed 12 Jun 2018.

25 Vapes C. F17 Herbal vaporizer. https://cloudvapes.com/f17-herbal-vaporizer (accessed 12 Jun 2018)

26 Eleaf. ICard. http://www.eleafworld.com/icard/ (accessed 12 Jun 2018).

27 Suorin. https://suorinairvape.com/pocket-vaporizer/ (accessed 12 Jun 2018).

28 Veppo. Suorin air pod vaporizer. https://veppocig.com/suorin-air-vaporizer/ (accessed 12 Jun 2018).

29 DaVinci. Ascent Vaporizer bundle. https://www.davincivaporizer.com/ascent-vaporizerbundle/ (accessed 12 Jun 2018).

30 TicTac-Toke, 2014. Review by Matt Gluggles https://www.youtube.com/watch?v=9pr2g6Fpto (accessed 12 Jun 2018).

31 Vaprwear. https://vaprwear.com/ (accessed 12 Jun 2018)

32 Kado Stealth Vaporizer. https://kadovapor.com/pages/about-us (accessed 12 Jun 2018).

33 Vaporizer USA. Atmos zig-zag stealth vaporizer. http://www.vaporizerusa.net/zig-zagstealth-tobacco-vaporizer.html (accessed 12 Jun 2018).

34 The Kind Pen Vaporizer. Discreet. http://www.thekindpen.com/product-category/ cbdiscreet/ (accessed 12 Jun 2018).

35 Jones I, 2016. Stealth Vaping: How to Become a Vaping Ninja: Vaping 360. http:// vaping360.com/stealth-vaping/.

36 Jac Vapour. Clear steam vaporless. https://www.jacvapour.com/e-liquid/clear-steam (accessed 12 Jun 2018).

37 White Cloud Electronic Cigarettes. E-Cig Mods vs. Cig-A-Likes/Mini Cigs: vapor production. https://www.whitecloudelectroniccigarettes.com/blog/e-cig-mods-vs-ciga-likes-mini-cigs-vapor-production/ (accessed 12 Jun 2018).

38 Zone V, 2017. Everything you need to know about stealth vaping. https://www. vapingzone.com/blog/stealth-vaping-techniques/ (accessed 4 Jun 2018).

39 Nick OG, 2018. How to JUUL, and vape in school the safest way. https://www. youtube.com/watch?v=qCVIOzQRUfM (accessed 10 Apr 2018).

40 Vapes V. Flavorless e-juices. https://vaporvapes.com/product/flavorless-e-liquid/ flavorless-e-juice/ (accessed 12 Jun 2018).

41 Lewis AC, 2017. Are Weed Vape Pens Safe? It's elegant, discreet and nearly odorless - but is vaping marijuana oil actually better for you than an old-fashioned joint? RollingStone. https://www.rollingstone.com/culture/features/are-weed-vape-penssafe-w507084 (accessed 12 Jun 2018).
42 Vape W. Stealth e-liquid. http://wake-n-vape.com/product/stealth-e-liquid/ (accessed 4 Jun 2018).

43 Wilson S, 2018. School district bans flash drives over confusion with e-cigarette brand. Fox 29. http://www.fox29.com/news/upper-dublin-school-district-bans-flashdrives-over-confusion-with-e-cigarette-brand (accessed 4 Jun 2018).

44 Hatcher C. JUULing is the new teen vaping fad taking over school bathrooms: Milwaukee Journal Sentinel, 2018. (accessed 4 Jun 2018).

45 Harris Z. Fed up with E-Cigarette and Cannabis use, High School Administrators look to vapor detectors: Merry Jane, 2018. (accessed 4 Jun 2018).

46 Digital Fly. Fly sense vaping sensor. https://www.digitalfly.net/flysense (accessed 12 Jun 2018)

47 Routliffe A. New trier high school considers stiffer anti-vaping discipline, adding vapor detectors: Chicago Tribune, 2018. (accessed 12 Jun 2018).

48 Wang TW, Gentzke A, Sharapova S, et al. Tobacco product use among middle and high school students - United States, 2011-2017. MMWR 2018:67:629-33.

49 Centers for Disease Control and Prevention. E-cigarette use triples among middle and high school students in just one year. https://www.cdc.gov/media/releases/2015/ p0416-E-cigarette-use.html (accessed 12 Jun 2018).

50 Cision PR Newswire, 2015. PAX Labs, Inc. granted U.S. patent for nicotine salt e-cigarette. https://www.prnewswire.com/news-releases/pax-labs-inc-granted-uspatent-for-nicotine-salt-e-cigarette-300196459.html (acessed 12 Jun 2018).

51 Willett JG, Bennett M, Hair EC, et al. Recognition, use and perceptions of JUUL among youth and young adults. Tob Control 2019;28:115-6.

52 Barrington-Trimis JL, Urman R, Berhane K, et al. E-Cigarettes and future cigarette use. Pediatrics 2016;138:e20160379.

53 McCabe SE, West BT, McCabe VV. Associations between early onset of e-cigarette use and cigarette smoking and other substance use among us adolescents: a nationa study. Nicotine Tob Res 2018:20:1-8.

54 Soneji S, Barrington-Trimis JL, Wills TA, et al. Association between initial use of e-cigarettes and subsequent cigarette smoking among adolescents and young adults: a systematic review and meta-analysis. JAMA Pediatr 2017;171:788-97.

55 East K, Hitchman SC, Bakolis I, et al. The association between smoking and electronic cigarette use in a cohort of young people. J Adolesc Health 2018;62:539-47.

56 Grana RA. Electronic cigarettes: a new nicotine gateway? J Adolesc Health 2013;52:135-6.

57 Sneed CD, Mehdiyoun NF, Matsumura SH, et al. Smoking on school property as a risk factor for substance use among adolescent smokers. J Psychol 2015;149:19-28.

58 Lindblom EN. Effectively regulating E-Cigarettes and their advertising and the first amendment. Food Drug Law J 2015;70:57-94

59 Benowitz NL, Goniewicz ML. The regulatory challenge of electronic cigarettes. JAMA 2013;310:685-6.

60 Yang YT. FDA's regulatory shift on tobacco control. Prev Med 2018;113:153-5.

61 European Commission. Tobacco products directive. https://ec.europa.eu/health/sites/ health/files/tobacco/docs/dir_201440_en.pdf (accessed 13 Jun 2018)

62 Linder-Ganz R, 2018. In blow to JUUL, Israel to ban some e-cigarettes. https://www. haaretz.com/israel-news/.premium-in-blow-to-juul-israel-to-ban-some-e-cigarettes-1. 6360627 (accessed 15 Aug 2018).

63 US Food and Drug Administration, 2018. Letter to JUUL. https://www.fda.gov/ downloads/TobaccoProducts/Labeling/RulesRegulationsGuidance/UCM605490.pdf (accessed 12 Jun 2018)

64 US Food and Drug Administration. Warning letters issued to retailers for selling JUUL to minors. https://www.fda.gov/TobaccoProducts/NewsEvents/ucm605278.htm (accessed 13 Jun 2018)

65 Reddit, 2018. JUUL sharpie stash. https://www.reddit.com/r/juul/comments/84izk9/ juul_sharpie_stash_3d_printed/ (accessed 4 Jun 2018). 